\title{
El laberinto económico mundial del nuevo-2000
}

\section{Introducción}

En febrero de 2000, Roberto Rivera Campos publica su estudio La economía salvadoreña al final de siglo. Desafios para el futuro. Se cierra una década de economía de mercado que no ha logrado los objetivos mayores propuestos en 1989: "crear las condiciones para erradicar la pobreza, lograr un crecimiento sostenido, reducir la participación del Estado en la economía y utilizar más plena y eficientemente los recursos del país" (pp.2-3). Al llegar al capítulo final de consideraciones y recomendaciones, Rivera Campos concluye: "La pérdida de productividad tendencial estaría en la base del bajo crecimiento logrado en el largo plazo. La persistencia de la pobreza es la otra característica de largo plazo de la economía" (p. 244). Cumplidos los cuatro primeros meses de 2000, "la economía aún no despega", no hay signos de reactivación ni en el sector real, ni en el sector monetario, al mismo tiempo que el poder adquisitivo de la población sigue disminuyendo. En este estado de emergencia se abre una ventana: ¿podrá la economía reactivarse si se cumplen los pronósticos de un fuerte crecimiento de la economía mundial? El pasado gobiemo, cerrando los ojos a las razones del estancamiento interno, lo explicaba por la contracción de la economía mundial y continental, a raíz de la crisis financiera mundial de julio 1997. Por la misma razón se esperaría que nuestra economía pueda reanimarse empujada por el viento del dinamismo mundial.

Son estas favorables expectativas las que me han llevado a hacer una incursión en la serie de cumbres y reuniones internaciomales, que se han realizado en cuatro de los continentes, en los cuatro primeros meses del año. El objetivo es ver nuestra economía desde esta perspectiva económica mundial, que, por supuesto, es bien heterogénea y llena de contrastes. La economía mundial es un mosaico de "euforia" (nueva economía de EEUU), mezclada con miedos (pánico bursátil); promesas de auge no seguidas del todo por los hechos consumados (zona del Euro); 
pesimismos con mezcla de esperanza (Bangkok, El Cairo, La Habana); cuestionamientos del FMI y Banco Mundial (Washington) y, recorriendo todo este itinerario, los manifestantes y las manifestaciones, que clausuran el $1^{\circ}$ de mayo, día internacional del trabajo. A nivel mundial cunde el cuestionamiento de la presente globalización, calificada hoy día como "la era de las desigualdades". A este entramado de situaciones lo he llamado "el laberinto económico".

Es difícil orientarse en este laberinto de la economía mundial, porque, a la par de la "nueva economía", la norteamericana, fluyen otras economías, la "Tercera Vía" europea, que todavía no sabemos si ellos saben hacia dónde quieren ir y, también, las cuartas y quintas vías donde los países "emergentes" parecen poder recuperarse, mientras que los pueblos "sumergentes" van relativamente hacia abajo. Podemos hablar de laberinto económico porque desde Seattle, OMC, noviembre de 1999, hasta Washington, FMI, BM, G-7, abril de 2000, los "manifestantes" y las demostraciones de protesta han recorrido el mapa mundial: Davos, Suiza, enero; Bangkok, Tailandia, febrero; El Cairo, en representación de África y La Habana, en representación del Grupo de los 77 no desarrollados, en abril de 2000. La policía trató de contener, por todos los medios, a los organizados manifestantes en la reunión del FMI y BM en Washington; también se dieron manifestaciones en la reunión de Praga, llevada a cabo en el otoño de este año. Necesitamos entrar en este laberinto económico mundial porque también nuestra economía es un tejido, mal cosido, hecho de retazos de Davos (nueva economía), de Tercera Vía europea, de "hombre de Seattle", de marginados de El Cairo y de La Habana y, por supuesto, con los creativos manifestantes que desde 1998 nos han legado una serie de estudios enrumbados hacia un plan de nación.

Con toda razón nos inquieía y nos ocupa un buen tiempo, el análisis de la coyuntura y evolución de nuestra economía nacional. Los institutos de investigación, los diarios y la televisión nos retroalimentan día a día con estos problemas y sus posibles soluciones. Al mismo tiempo, una apertura y un breve seguimiento de estas reuniones mundiales, en los distintos continentes, nos ayudará a entender mejor y a orientar nuestra economía nacional desde el laberinto de la economía mundial. Si los "manifestantes" son un signo de nuestro tiempo, quiere decir que ha llegado la hora de la búsqueda y de la creatividad, donde ningún modelo es "el fin de la historia" y donde queda espacio para "otras nuevas economías". Con este propósito nos servimos del Internet para recorrer algunos rincones del planeta.

\section{Más allá de la "Tercera Vía"}

Tal como comienzan a soplar los nuevos vientos del 2000 parece que los conductores de la "tercera vía" europea van a dejar en el andén de la estación a los pasajeros del "tercer mundo". Nos sonaban correctas las últimas frases de A. Giddens: "Los problemas globales responden a iniciativas locales, pero exigen 
también soluciones globales. No podemos dejar tales problemas a merced del errático torbellino de los mercados mundiales y de los relativamente impotentes cuerpos internacionales, si queremos crear un mundo que combine estabilidad, equidad y prosperidad". A. Giddens dedica el último capítulo a una utopía: "hacia la era global", el mundo cosmopolita de la socialdemocracia, que venga a remediar "la profunda división económica en la sociedad actual. Hay un paralelismo entre la exclusión dentro de las naciones y regiones, y la exclusión a escala mundial. Una prosperidad creciente para muchos deja a otros sin recursos y marginados". (Giddens, A.: La tercera via: la renovación de la socialdemocracia. Taurus, 1999; pp. 179 y 178). Estas frases, en su versión original, fueron escritas en 1998, pero una secuencia de hechos y reuniones no nos dejan ver claro hacia dónde quieren ir o quieren llevarnos los "actores" de la Tercera Vía.

En noviembre de 1999 se reúne el XXI Congreso de la Internacional Socialista y sus 170 partidos miembros firman la Declaración de París. Los seis puntos principales de agenda significan un compromiso de gobernar la globalización, reestructurando las principales instituciones internacionales para adaptarlas a las nuevas realidades, declarando una "lucha contra la pobreza y el hambre, contra la explotación y la desigualdad de acceso a los recursos económicos y tecnológicos mundiales, más el apoyo a la anulación de la deuda extema de los países más pobres". (ECA, 2000; p. 60) Parecía que en esta declaración los actores de la Tercera Vía se presentaban como defensores y protectores de los países del tercer mundo, al cual pertenecen la mayoría de partidos afiliados a la Internacional Socialista.

Un mes más tarde, diciembre de 1999, tiene lugar la cumbre de la Organización Mundial del Comercio (OMC) en Seattle, EEUU. Desgraciadamente, y así tenía que ser, esta cumbre de la OMC divide al mundo en tres bloques difícilmente reconciliables. Aparte del enfrentamiento de las trilaterales norteamericana y europea, se profundizan los recelos y la cólera del hemisferio Sur en contra del Norte. Además de los nunca olvidados 40.000 manifestantes de Seattle, los representantes de los países en desarrollo se niegan a ratificar un acuerdo final, cuando no habían sido consultados ni escuchados en la preparación de los previos borradores. Este inesperado y justificado rechazo ha sido interpretado como una victoria del tercer mundo. La Organización Mundial del Comercio debe aprender a escuchar y hacer partícipes de sus decisiones a todos los miembros de la institución. (ECA, 2000; p. 60-69) Esta escisión de la geografía económica mundial dejaba planteado un interrogante: los representantes de la Unión Europea, principales actores de la Tercera Vía y primeras firmas de la Declaración de París, ¿hacia qué lado del péndulo o de los paralelos económicos se deslizarán en el año y siglo nuevos?

En enero de 2000 llegan los convocados a la reunión anual del foro económico de Davos, que concentra a la élite del capitalismo. También aquí se hizo presen- 
te el "fantasma de Seattle" y los nuevos manifestantes la calificaron como "el politburó de la internacional capitalista". Davos-2000 fue la cumbre de la "nueva economía", la exaltación del prolongado auge de la economía norteamericana (107 meses de crecimiento ininterrumpido con baja inflación). Euforia de la exuberante racionalidad de su bolsa de valores y la presentación de la nueva vía del crecimiento futuro, el tótem del Internet, que engloba a 200 millones de afiliados en 134 países del planeta. Esta nueva vía de apertura a toda clase de ventas y relaciones comerciales auguraba un crecimiento mundial superior al 4\%. La "nueva economía" desacreditaba y silenciaba las perturbaciones de Seattle, al mismo tiempo que los "europeos" escuchaban la lección como atónitos alumnos. Surgía así la imagen del "hombre de Davos" frente al "hombre de Seattle".

Ante el triunfalismo de los ponentes norteamericanos ("llegar, ver y vencer"), algo tenían que hacer y decir los europeos para no aparecer como niños de escuela. Este fue el papel de Tony Blair, que ensalzó con entusiasmo las virtudes de la nueva economía y auguró que la Unión Europea pretende "recuperar el liderazgo de la nueva economía que elevaría el nivel de los ingresos". No es de extrañar que Tony Blair se llevara los mayores aplausos de Davos, dejando atrás a Bill Clinton, quien dijo que convenía prestar alguna atención a los manifestantes de Seattle y Davos, para ganarlos a la causa de la globalización, (ECA, 2000; pp. 121-127). Este liderazgo de Tony Blair en Davos se hará presente, con mayor fuerza, en la próxima reunión de la Unión Europea en Lisboa.

Así entramos en el complejo laberinto de cumbres y reuniones sostenidas en los cuatro primeros meses del 2000. Del 14 al 18 de febrero se reúne en Bangkok, Tailandia, la décima Conferencia sobre Comercio y Desarrollo Económico, que organizan cada cuatro años las Naciones Unidas. Los días 23 y 24 de marzo se congregan en Lisboa los representantes de los gobiernos europeos para dilucidar el futuro de Europa, comprometiéndose, con mayor o menor realismo, a montarse en el tren de la "nueva economía", programando - calendario en mano- una serie de medidas destinadas a integrar las tecnologías de telecomunicaciones e Internet, a nivel de Unión y de instituciones educativas o de investigación en cada país. En un escenario muy distinto tiene lugar en El Cairo, Egipto, los días 3 y 4 de abril, durante la primera cumbre entre la Unión Europea y países de África. Los europeos no hacen propuestas concretas a los representantes del continente más pobre y más agobiado por la deuda externa, las guerras internas, la corrupción pública y la plaga del SIDA... La globalización es un fenómeno extraño a este continente, calificado como maldito, y los europeos escucharán algo de historia africana, desde que en 1888 se firmó en Berlín el reparto del continente entre los colonizadores del Norte. Un continente rico habitado por una inmensa mayoría de pobres...

No se hizo presente a esta reunión Kofi Annan, Secretario General de Naciones Unidas, por estar presentando en las mismas fechas "el plan de acción de las 
Naciones Unidas para el siglo XXI: ¿Cómo abrir un espacio a los países agobiados por la pobreza y la deuda externa a los aportes tecnológicos y financieros de la globalización?". Con similar calendario, 11-16 de abril, y en dos escenarios distintos, tiene lugar la cumbre del Grupo de los 77 (G-77), ¿antiguos no-alineados?, que no se reunían desde 1970, convocados en La Habana para analizar los efectos de la globalización Norte-Sur; mientras que en Washington se abre la reunión de primavera del FMI, BM y el G-7, para diseñar el futuro del mundo. Esta reunión se inicia bajo el "síndrome de Seattle", con unos 200 grupos de pluriformes manifestantes que claman por una "justicia global". En las mismasfechas, y sin mucho clamor, se reúnen en Bruselas algunos representantes de la Internacional Socialista, advirtiendo "contra los peligros de una globalización descontrolada, que aporta más inconvenientes que ventajas y aumenta la distancia entre ricos y pobres". Tal vez, lo más importante de esta reunión es que los representantes europeos se preguntan si no hay una contradicción entre lo que los socialistas defienden en las reuniones de la Internacional Socialista y lo que deciden en la Comisión Económica y Consejo Europeo. Felipe González dice: "éstas son contradicciones consubstanciales al poder político". (El País, 11 de abril de 2000). La pregunta es si los poderes políticos quieren y pueden resolver estas contradicciones o si nos seguimos enfrentando con crecientes contradicciones. Es, más bien, esta segunda alternativa la que se estaría gestando en esta secuencia de cumbres y reuniones mundiales.

\section{Europa, entre Bangkok y Lisboa}

Del 12 al 19 de febrero tuvo lugar en Bangkok, Tailandia, la décima conferencia sobre Comercio y Desarrollo que organizan cada año las Naciones Unidas. El objetivo es promover el desarrollo, sobre todo de los países pobres, a través del comercio internacional. Aunque en estas conferencias no se firman compromisos vinculantes, estaba aún muy fresca la imagen de Seattle, el rechazo de los países en desarrollo a ratificar convenios sin previa escucha y consulta. Aquí son los países pobres quienes piden mayor apertura para sus exportaciones primarias y, más en particular, la apertura total para las exportaciones de los 48 países más pobres y endeudados del tercer mundo, cuyas exportaciones representan sólo un $0,5 \%$ del comercio internacional. Una forma directa e indirecta de aliviar su deuda externa es ampliar la apertura a sus exportaciones. De la acumulación de la deuda creciente y de las restricciones comerciales se deriva la retroalimentación de la pobreza y desigualdad, que caracteriza a la actual globalización.

Los representantes de las naciones desarrolladas pudieron escuchar el último discurso de Michel Candessus, presidente saliente del FMI: “...Si se trata, entonces, de una poderosa dinámica (la globalización) que promete un mundo mejor, ¿por qué tanta ansiedad y por qué tantos la rechazan como un símbolo de las nuevas tendencias económicas? La respuesta es que aún no se ha demostrado 
que la globalización se preocupe lo suficiente por el problema más grave de esta era, la pobreza, o que sea capaz de resolverlo". Esta afirmación de M. Candessus es muy seria, a modo de un legado para los representantes de las naciones poderosas. Nótese que es una reflexión de un presidente del FMI, acusado de haber propiciado con sus políticas económicas esta situación de pobreza y desigualdad. "La creciente brecha entre los ricos y los pobres, y el abismo que separa a los países más ricos de los más pobres, son moralmente inadmisibles, económicamente ineficientes $y$, desde el punto de vista social, potencialmente explosivos. Hoy es evidente que no basta aumentar el tamaño de la tarta; la forma en que se reparte es esencial para el dinamismo del desarrollo. Si no ofrecemos esperanza a los pobres, la confrontación, la violencia y las conmociones civiles terminarán socavando la estructura de la sociedad. En ninguna parte podemos permitimos el lujo de hacer caso omiso de la pobreza, pero es en los países pobres donde ya no puede tolerarse la extrema pobreza. Es nuestro deber aunar esfuerzos para aliviar el sufrimiento"... (Boletín del FMI. 24 de febrero de 2000; p. 51)

Pese al discurso de M. Candessus y al informe introductorio de Rubens Ricupero, Secretario General de la UNCTAD, los representantes de los países desarrollados no se comprometieron a abrir sus fronteras, ni siquiera a los 48 países más pobres. Aún en este caso se prefirió una fórmula vaga y limitante, haciendo referencia a "lo esencial de los productos exportados", y no a todos ellos. De acuerdo a los reportes de agencias, "El tema agrícola amenaza con arruinar la cumbre, igual que en Seattle". Al frenar el ingreso de productos agrícolas y aplicar contingentes a los tejidos y prendas de vestir, las naciones industrializadas dañan especialmente al sector pobre campesino y al elevado grupo de mujeres que laboran en la confección del vestuario. No se entiende la doble moral de los gobiemos que dicen querer aliviar la pobreza y la deuda del tercer mundo al mismo tiempo que cierran el ingreso de estas exportaciones básicas y competitivas con medidas arancelarias y no arancelarias. Los economistas clásicos y liberales del siglo XIX nos enseñaban que en el comercio internacional salían favorecidos ambos intercambistas; con el advenimiento de la globalización neoliberal, esta teoría cae por tierra por obra y gracia de las naciones poderosas.

A esta contradicción se agrega un tema adicional que levantó muchas suspicacias en Seattle, Davos y Bangkok. "Los delegados (europeos y norteamericanos) insistieron en que el crecimiento económico pasa por el respeto de los derechos humanos, la protección del medio ambiente y la aceptación de las normas laborales internacionales". Es muy cierto que bastantes países del tercer mundo incumplen esta trilogía de deberes, pero no son los gobiernos y empresas del primer mundo quienes están más limpias de pecado. Los EEUU no han ratificado la mayoría de acuerdos de la Organización Internacional del Trabajo (OIT); algunas multinacionales del Norte siguen siendo criticadas por ocupar mano de obra infantil en países pobres, $y$, por lo que toca a la protección del medio ambiente, han sido los mayores depredadores. Los EEUU tampoco han querido 
firmar el Protocolo de Kyoto (1998) sobre la reducción de gases de efecto invernadero; ni el Tratado de Proliferación Nuclear (1999); tampoco el Tratado de Minas Antipersonales (1999)... Estas reiteradas negativas no favorecen mucho la defensa del medio ambiente.

En esta reunión de Bangkok, Tailandia, epicentro de la crisis financiera de julio de 1997 , no podían faltar las alusiones y sugerencias sobre la reforma del sistema financiero internacional, que en pocas semanas dislocó estas florecientes economías del sudeste asiático, aunque su propio sistema bancario fue copartícipe de esta debacle. No es de extrañar que M. Camdessus, presidente del FMI, fuera despedido con un pastelazo de crema tailandesa. Tal vez el recuerdo de Seattle explica que los representantes de los países desarrollados no quisieran comprometerse en Bangkok con promesas concretas, que fueran luego utilizadas como puntos de agenda a ratificar en Ginebra, sede la Organización Mundial del Comercio. Como hemos comentado en artículo más amplio, en Bangkok los países desarrollados tuvieron la oportunidad de escuchar las solicitudes y requerimientos de los países pobres y más pobres, para quienes la globalización es un poder siniestro y fuera de control. Por su parte, los países en desarrollo han podido reflexionar sobre las dificultades extemas y los limitantes internos, detallados en el informe de R. Ricupero, que dificultan su participación en las posibles ventajas de la globalización y que, en consecuencia, requieren reformas y programas económicos de nación. (Ibisate, F. J.: Nueva economía 2000: nueva brecha entre Norte y Sur. Realidad, noviembre - diciembre 1999; pp. 664-668)

\section{Lisboa, el espejismo de la "nueva economía"}

En la cumbre de Jefes de Estado y de Gobiemo de la Unión Europea se actualiza una nueva edición de El desafio americano, escrito por Jean Jacques ServanSchreiber en 1967. Baste leer la introducción o la carátula de este libro que sacudió la atención de Europa, integrada ya en su Mercado Común. "La gran revolución que se opera en el mundo no es política ni es ideológica. Es simplemente tecnológica, económica y administrativa. Los descubrimientos técnicos y el manejo inteligente y fecundo de recursos impulsan el desarrollo económico, y éste trae grandes cambios sociales..."; "el desafío americano plantea la creación de un mundo futuro a punto de surgir. Este mundo será mucho más rico y nivelará las desigualdades. Pero no nacerá sin esfuerzo. Para desarrollarlo se necesitan, sobre todo, inteligencia, educación y sentido de la realidad. Las computadoras electrónicas, capaces de memorizar todas las informaciones de las bibliotecas del mundo, la aeronáutica, que permitirá comunicaciones vertiginosas, la economía a escala sideral, cambiarán la fisonomía de los países". (Servan-Schriber, J. J.: El desafio americano. Ed. Denoël, París, 1967) Como luego sobrevino la crisis de 1970 y la nueva enfermedad de la estanflación, El desafio americano pasó a descansar en el limbo de las bibliotecas; volvemos a recordarlo ahora que aparece su edición actualizada con el hombre de "la nueva economía americana", a 
modo de nuevo desafío para la Europa del euro y del continente integrado. Baste citar algunos titulares de las agencias que nos comentan la cumbre de Lisboa, celebrada los días 23 y 24 de marzo de 2000. "La UE debate en Lisboa su reforma económica para competir con EEUU"; "Estados Unidos frente a Europa"; "La cumbre europea de Lisboa ratifica una visión liberal del futuro de Europa"; "Los Quince liberalizan las telecomunicaciones para responder al reto de la nueva economía", "La Europa de Blair empieza en Lisboa"; "La nueva economía y sus metáforas"...

Desde nuestro tercer mundo, i,por qué y para qué dedicar tiempo y páginas a esta cumbre de la Unión Europea, donde ellos deliberan sobre su destino futuro? Hay varios aspectos que pueden afectar también a nuestro porvenir. ¿Qué traducción histórica se va a dar a los objetivos sociales planteados en la "Tercera Vía": estabilidad, equidad y prosperidad? ¿Cuál será el modelo inspirador? ¿Qué significa, en concreto, el eufemismo de "modernización del modelo social" y que "frente al socialismo de rostro humano" emerge "el liberalismo de rostro humano"? ¿Qué queda de la Declaración de París, firmada en noviembre de 1999 por los 170 partidos miembros de la Internacional Socialista? ¿Comienza Europa a engavetar los grandes principios de igualdad, fraternidad, solidaridad..., propios del Estado social de bienestar? La razón de plantear estas preguntas es que la cumbre de Lisboa ha sido liderada por los representantes de centro-derecha y su parámetro de referencia es la nueva economía norteamericana.

Siendo realistas, la Unión Europea, como bloque, se halla inquieta por su sensible rezago tecnológico y económico frente a los Estados Unidos. Claramente se lo espetaron en Davos. Abby Joseph Cohen, de Goldman Sachs, les recordó que "la economía estadounidense ha creado 16 millones de empleos en los cinco últimos años, mientras que Europa perdía un millón". (ECA, 2000; p.122) También se dijo que "el país de vanguardia en la era de la revolución informática será más poderoso que cualquier otro... En el futuro previsible, este país es Estados Unidos... La información es la nueva moneda del reino internacional y Estados Unidos está mejor situado que cualquier otro país para hacer valer su potencial de recursos materiales y logísticos por la vía de la información"... (ECA, 2000; p. 71)

Por ello, Tony Blair quiso dejar en Davos la imagen de un líder modernizador; ensalzó con entusiasmo las virtudes de la nueva economía y definió tres principios de su gobierno: "rigor monetario, cambio acelerado de la estructura industrial y apoyo a los proyectos de nuevas tecnologías de las pequeñas empresas, y reforma de los sistemas de bienestar y de los mercados laborales". Tony Blair dijo que la reforma de la Unión Europea pretende "recuperar el liderazgo de la nueva economía", Así, Tony Blair se constituye en el jefe de fila de la cumbre de Lisboa. (La Europa de Blair comienza en Lisboa. El País, 8 de abril de 2000). 
La Comisión Europea establece cuatro objetivos estratégicos para el período 2000-2051, en respuesta a cuatro interrogantes. "El primero se refiere a cómo mejorar las actuales formas de gobierno europeo. El segundo, cómo dar respuesta al triple desafío de las perturbaciones geopolíticas, de la mundialización y de la poca fortaleza del sistema internacional. El tercero, cómo hacer de la Unión Europea (UE) una economía competitiva en el plano mundial, que se traduzca en una mejora sustancial del nivel de empleo. Por último, el cuarto se refiere a cómo conseguir que los ciudadanos europeos perciban que su pertenencia a la UE contribuye a la mejora de su calidad de vida". No hay lugar para extenderse en estos cuatro objetivos, recordando simplemente que Europa es un multicolor mosaico de países con sus ancestrales culturas, variadas lenguas, abiertos ahora a la integración de nuevos países que quieren integrarse en la Unión y también en la OTAN. Los ruidos de Serbia-Kosovo y de Chechenia son fuertes; los efectos de la mundialización son dramáticos para los países de ultramar y ya se vaticinan las tensiones sobre el futuro del FMI y BM en la próxima reunión de Washington. Al interior de la Unión Europea se busca un centralismo democrático, donde los gobiernos y ciudadanos de cada país cooperen en los diferentes niveles de poder. Se habla de una descentralización radical y de cooperación entre los distintos niveles de gobierno.

Nos centramos en la "nueva agenda económica y social". Lo que se busca es "la modernización de la economía europea, que le permita acceder a la nueva era digital, favoreciendo el empleo así como el desarrollo duradero, y reformando nuestro sistema de protección social, que permita construir una sociedad más equitativa". El Consejo Europeo fija dos ejes principales: "El primero se refiere a la prosecución de la reforma económica para prepararse a la nueva economía. El segundo se basa en invertir en capital humano y consolidar el modelo social europeo". A este fin se calendarizan una larga serie de medidas, con años-fecha de realización, que a través del impulso al comercio electrónico y de la liberalización del mercado interior logre "un crecimiento económico estable, que permita reducir el desempleo - el objetivo ideal es el pleno empleo- y sostener un modelo de bienestar social cuya reforma debe ir en paralelo a la extensión del mercado interior. El consenso en el aspecto social es claro: reformar la asistencia para hacerla sostenible y garantizar recursos suficientes para evitar la exclusión social". (Larraya, J.M. y García, J.: La UE debate en Lisboa su reforma económica para competir con EEUU. El País, 23 de marzo de 2000) Esta última frase trasluce las reflexiones del capítulo cuarto de la Tercera Vía: "El Estado social inversor. El significado de la igualdad. Inclusión y exclusión. Una sociedad de bienestar positivo. Estrategias de inversión social".

Más allá de la curiosidad, el interrogante es la inspiración ideológica que subyace bajo estas propuestas económicas, abanderadas sobre todo por Tony Blair y el reelegido presidente español, José María Aznar. Los comentaristas de Le Monde algo indican en su titular: La cumbre europea de Lisboa ratifica una 
visión liberal del futuro de Europa. Aunque ministros y Jefes de Estado digan que no hay debates ideológicos entre los partidarios de la Tercera Vía de Tony Blair y una "izquierda a la francesa" de L. Jospin, lo cierto es que "los gobiernos europeos se han puesto de acuerdo, en un clima plenamente sereno, para adoptar una estrategia de crecimiento y empleo fuertemente impregnada de liberalismo. La razón es que se trata de una globalización de la economía dominada por las fuerzas de mercado". Así lo manifestó el presidente del gobiemo español, Aznar, quien "se regocijó del "viento liberal" que sopla sobre Europa, único camino, según él, de llegar al pleno empleo, un objetivo que el crecimiento económico no lo convierte en utópico". Los reporteros de Le Monde dejan caer algunos comentarios realistas. Se pretende crear 20 millones de empleo en diez años, en una Europa que tiene actualmente 15 millones de desempleados. Este objetivo es una muestra del optimismo del presidente de la Unión Europea, Antonio Gutiérrez (socialista), sobre las potencialidades de la "sociedad de la información": "de todas formas, este mensaje de esperanza no puede hacer mal a la opinión pública europea".

Incluso se percibe un sesgo gramatical en la redacción de los objetivos: no se habla de reducir el "paro", sino de lograr el pleno empleo. "Es necesario constatar que en las conclusiones de los Quince no se hace mención de la reducción del "desempleo" europeo de $8,8 \%$ a $4 \%$; de una reducción de la tasa de pobreza en Europa del $18 \%$ al $10 \%$ en 2010 , objetivos que habían sido propuestos por la presidencia portuguesa". La única concesión fue una "agenda social europea" y un calendario que fije "una verdadera legislación social europea". En Lisboa se ha enfatizado el concepto de "Estado social activo", término preferido por Tony Blair" (de Bressont, H. et Zechini, L.: Le sommet européen de Lisbone entérine une visión libérale de l'avenir de l'Europe. Le Monde, 25 mars 2000).

Walter Openheimer, redactor de El País, opina que "la Cumbre de Lisboa puede pasar a la historia o quedarse en un fiasco. Pasar a la historia, porque suponga un cambio fundamental en el mensaje político-económico de la Unión Europea y un relevo de liderazgo generacional. Un fiasco, porque ese mensaje, de gran fuerza política, no se ha apoyado en decisiones de calado. El viaje a la nueva economía se quiere hacer con las alforjas llenas, sobre todo, de liberalismo y retórica". Openheimer cree que los objetivos de alcanzar la tasa de ocupación de los Estados Unidos en diez años, lograr así el pleno empleo, implantar el Internet en todas las escuelas e incrementar las inversiones en información..., parece más bien un catálogo de ideas que un plan de acción bien anclado. No hay un proyecto de mercado único europeo de telecomunicaciones, sino referencias genéricas de preparar un plan de acción sobre comercio electrónico, o de "ultimar" un paquete fiscal, de suprimir los trámites burocráticos para la creación de empresas. Lo que sí se aprecia es un cambio generacional en la Unión Europea, donde la vieja guardia cede el paso a la Europa de Tony Blair, Gerhard Schröder, José María Aznar y Massimo D’Alema. Ellos pretenden ser la modernidad que se mira más en el modelo americano. 
"En Lisboa ha sonado la hora del liberalismo, la llave con la que Europa quiere abrir las puertas a la nueva economía para atrapar y superar a Estados Unidos. La receta es sencilla: liberalizar la actividad económica - con las telecomunicaciones como faro-, mantener la política de reformas estructurales y de saneamiento de las finanzas públicas, modernizar (¿eufemismo de recortar?) los sistemas sociales". En Lisboa se ha hecho el elogio del mercado frente a la intervención pública, como receta única. "Frente al socialismo de rostro humano emerge el liberalismo de rostro humano”... “ ¿Se ha convertido la Unión Europea en una pirámide de amplia base con vértice en Londres? ¿Manda Blair en Europa?”

Openheimer sostiene que este acercamiento a la nueva economía norteamericana no está exento de serias contradicciones. "El mensaje de Lisboa se aferra tanto a lo constructivo, lo positivo, que olvida subrayar algunas de las diferencias fundamentales que separan a Europa del mito que persigue, Estados Unidos. El modelo estadounidense es el del crecimiento vertiginoso, el éxito individual, la libertad de empresa, la implantación arrolladora del Internet. Pero también es un germen de exclusión social, de racismo, de subempleo, de incultura, de carencias sanitarias, de aumento de la pobreza. Un modelo basado no sólo en la innovación tecnológica, sino en el despido libre inmediato, una movilidad geográfica lindante en el desarraigo, los precios baratos del carburante sin reparar en sus consecuencias medioambientales. ¿Se puede ser EEUU y seguir siendo Europa?". (Openheimer, W.: La Europa de Blair empieza en Lisboa. El País, 8 de abril de 2000)

\subsection{El círculo virtuoso de la nueva economía}

Aunque nos hallamos en la periferia de la nueva economía, lo cierto es que este concepto y esta práctica son uno de los ejes centrales sobre los que gira la economía mundial. Por otra parte, a las teorías se suman las preocupaciones. Mientras que los participantes de la reunión de primavera del FMI, BM y G-7, celebrada del 12 al 16 de abril, preconizan un crecimiento mundial superior al $4 \%$, otros grupos e instituciones se preguntan si el aterrizaje de la economía americana será suave o brusco, y si sus consecuencias mundiales serían de menos a más represivas; al mismo tiempo, se anuncia el despegue de Europa, como una respuesta psicológica al compromiso de Lisboa, de encaramarse en el tren de la nueva economía. En la reunión de Washington se pedirá a Europa y a Japón que traten de elevar sus tasas de crecimiento a fin de que los Estados Unidos no se vean obligados a frenar su propio crecimiento, como primera locomotora del $25 \%$ de la producción mundial. No está de más preguntarnos qué hay dentro y después de la nueva economía.

Guillermo de La Dehesa, presidente del Centre for Economic Policy Research (CEPR) de Londres, compara el nivel de aplicación de la nueva economía entre Estados Unidos y Europa. El artículo se inicia con una definición. "La llamada 
nueva economía no es otra cosa que el rápido desarrollo y aplicación de las nuevas tecnologías de la información, que está permitiendo el paso de una economía basada en la producción industrial de bienes a otra soportada por la provisión de servicios basados en el conocimiento, las ideas y la información. Es decir, es un cambio desde una economía basada, fundamentalmente, en el uso del capital físico a otra erigida sobre la utilización de capital humano, desde una economía básicamente material a otra intangible. Es la revolución tecnológica que va a marcar el desarrollo del siglo XXI, al igual que la revolución industrial lo hizo en el siglo XIX. Los factores básicos de dicha nueva economía son, por un lado, un elevado nivel de educación, especialmente científico-técnica. Por otro, un rápido desarrollo de la informática y de las tecnologías de la comunicación. Además, unos mercados de capitales que incentiven la inversión en capital riesgo y, finalmente, un espíritu emprendedor en la sociedad en general”. “¿Cómo se encuentra Europa frente a los Estados Unidos en el desarrollo de esta nueva economía?". El autor prolonga en cuatro páginas este análisis comparativo y su conclusión nos hace sentir lo que Joaquín Estefanía describe como la "globalización mutilada": "Si no se permite y se promueve una transición rápida desde los sectores económicos basados en el capital físico y la mano de obra poco especializada a los sectores basados en capital humano y en la producción de bienes y servicios de media y alta tecnología, las diferencias de productividad y renta entre Estados Unidos y Europa aumentarán aún más en los próximos años". (De La Dehesa, G.: Estados Unidos frente a Europa. El País, 18 de marzo de 2000) Aunque un tanto alejados de esta "nueva economía", tal vez sea interesante escuchar algo sobre su "círculo virtuoso" y en qué grado encuentra aplicaciones concretas a nuestra realidad.

Una semana más tarde, Jesús Banegas, dirigiéndose al ciudadano europeo, hace el panegírico del "círculo virtuoso" de la nueva economía, cuyas características y reglas de juego escapan de la ortodoxia neoclásica. "La competencia imperfecta parece ser inherente a la economía del conocimiento. Las ventajas iniciales se convierten en permanentes e irreversibles... La economía deviene virtuosa. Hoy es posible incrementar la producción, la productividad y el empleo simultáneamente. Las nuevas tecnologías, lejos de generar externalidades negativas, en forma de contaminación, agotamiento de materias primas, etcétera..., sólo ofrecen economías externas positivas que benefician a los demás sectores productivos y de servicios, y con ellos a la sociedad toda. El sector electrónico y de comunicaciones, en su conjunto, funciona y se desarrolla contradiciendo la teoría económica convencional, según la cual el crecimiento de la demanda produce una subida de los precios. En realidad, la expansión de la demanda de tecnologías de la información hace bajar los costos, y con ello los precios, que a su vez animan y hacen crecer aún más la propia demanda". "Se trata de un "círculo virtuoso" que, en la medida en que el sector participa crecientemente en la economía, afecta positivamente a ésta, contagiándola con sus bondades... El nuevo 
ciclo económico, es evidente, está cada vez más vinculado a la salud del sector electrónico y de telecomunicaciones, que viene creciendo muy por encima de los demás sectores y ayuda a la expansión del PIB. Según la teoría del ciclo tradicional, los precios suben y la productividad crece hasta que las fábricas alcanzan el límite de su capacidad/En el sector electrónico, el crecimiento de la demanda hace bajar los costos de producción y, como consecuencia, los precios, lo que a su vez refuerza la demanda; según un círculo económico virtuoso que no genera inflación, y que por tanto, desde esta perspectiva, no pone fin a la parte alcista del ciclo. Una de las claves de mantenimiento de un inusual largo ciclo de crecimiento de la economía se debe a que el típico recalentamiento de la misma por un aumento de la demanda que hace crecer los precios y con ellos los tipos de interés, no se produce, porque el incremento de la demanda es absorbido por un incremento de la productividad..."

Luego de fundamentar esta teoría con datos de la economía española de 1998, Banegas afirma que los servicios no son necesariamente el signo de la nueva economía postindustrial, porque la nueva sociedad de la información y el conocimiento depende en última instancia de la industria que los posibilita: "el peso económico relativo del mercado de la industria y de los servicios es equivalente... Los países precursores de la nueva economía, los EEUU y los nórdicos europeos, además de liderar el consumo de las tecnologías de la información, están liderando también el desarrollo tecnológico y la producción industrial de las nuevas herramientas de la Sociedad de la Información". (Banegas Núñez, J.: Impactos de las tecnologías de la información en la nueva economía. El Pais, 25 de marzo de 2000)

Esta es la nueva economía del siglo XXI, que nos interesa conocer o reconocer, porque tal vez nos caigan algunas migajas de la mesa de los ricos por inversión directa o por un proceso de adecuado aprendizaje. También hay autores que ponen en duda toda esta pureza y euforia del mercado. Joaquín Estefanía habla de "La nueva economía y sus metáforas". Doce días antes del "viernes negro", 14 de abril, Estefania dice: "El ímpetu arrollador de esta nueva $\in$ conomía también ha tenido estos días contrapesos que apelan a la prudencia de quienes creen que en su naturaleza está siempre ir hacia arriba y no consideran vigentes las lecciones de la historia que nos indican que las burbujas financieras siempre han acabado deshinchándose, a veces de forma dramática”. Cita a Luis Ángel Rojo, gobernador del Banco Central de España, que, al igual que Alan Greenspan, ha seguido la estela de la "exuberancia irracional de los mercados". "La bolsa americana, dijo Rojo, al exceder de los valores justificables por los fundamentos económicos, tendría actualmente un componente mayor o menor de burbuja financiera, insostenible antes o después. La nueva economía no ha relegado a la historia los riesgos inflacionistas, ni las fluctuaciones cíclicas de la economía". Se pregunta el gobernador:" $¿$ Se trata de revalorizaciones bursátiles que tienen una base sólida? ¿Se trata, por el contrario, de burbujas financieras 
cuya explosión podría dañar gravemente la demanda y la actividad de la economía mundial?".

Con estas preguntas, Joaquín Estefanía aterriza en la reunión de Lisboa. "Con sus pros y sus contras, la nueva economía ha adquirido carta de naturaleza en la cumbre de Jefes de Estado y de Gobiemo de la Unión Europea, reunidos hace unos días en Lisboa. Lo más importante de la misma ha sido que por primera vez la atención de los líderes europeos ha girado desde lo monetario al pleno empleo. Lo más discutible es que, debajo de las palabras, de los objetivos y los calendarios, no se han puesto o no se han explicitado los medios para poner en marcha esa nueva economía: cómo va a ser financiada. Se ha tratado más de crear ambientes que de ser concretos. Como si la nueva economía fuera lo políticamente correcto en esta nueva etapa de la coyuntura... La nueva economía se compone todavía de realidades y de metáforas. Y hay que distinguirlas". (Estefanía, J.: La nueva economía y sus metáforas. El País, 2 de abril de 2000)

De hecho, a inicios de mayo se reconoce que Europa no acaba de despegar y que más bien se amplían las distancias con el modelo de ultramar: "El euro cae por debajo de los 90 centavos de dólar y coloca a Europa en situación límite". El País, 4 de mayo. La debilidad del euro genera tensiones entre los miembros de la unión monetaria. El País, 7 de mayo de 2000)

Si la nueva economía es un tema inconcluso para Europa deducimos las crecientes distancias que el proceso de globalización está gestando, de acuerdo a la nomenclatura actual, entre los "países informatizados" y "no informatizados". Por ello hablamos del laberinto económico del 2000, del posible camino que nos corresponde seguir en el próximo futuro. Al mismo tiempo que los medios de comunicación acercan todos los rincones del mundo, la nueva economía del conocimiento informatizado agranda las distancias económicas. Siguiendo el orden cronológico de estas reuniones mundiales, aterrizamos ahora en el continente más alejado de la nueva economía.

\section{La reunión de EI Cairo: "la globalización mutilada"}

Los días 3 y 4 de abril tiene lugar en El Cairo la reunión de representantes de la Unión Europea con jefes de Estado del continente africano. En esta reunión entramos en el lado menguante de la globalización, que Joaquín Estefanía define como "la globalización mutilada". "Durante la última semana hemos visto, más descarnadas que nunca, las dos caras de la globalización; por un lado, la extrema volatilidad de unos mercados que se contagian de euforia y de tristeza a velocidad de vértigo; por el otro, todo un continente africano para el que la globalización no es más que un concepto extraño e importado, y al que no llegan las migajas del capitalismo mundial. Mientras hay una parte del mundo que está viviendo de forma acelerada una segunda revolución del capitalismo, hay otra que está todavía por disfrutar a fondo de la revolución industrial... La globalización ha tenido 
:omo efecto positivo la creación de un nuevo grupo de países, los emergentes, jue se han desprendido del Tercer Mundo y aprovechan las ventajas de la circuación de capitales para aumentar el bienestar de sus ciudadanos. En sentido zontrario, ha dejado a expensas de su miseria a los llamados países pobres - la nayoría de los africanos- a los que Occidente ni siquiera ha condonado su leuda externa". (Estefanía, J.: La globalización mutilada. El País, 9 de abril de 2000)

Esta es una buena introducción a la cumbre de El Cairo, donde ministros de isuntos exteriores de 72 países participantes en la cita euroafricana intentan 'salvar el abismo que separa a África de la globalización". Se trata de un camjio brusco de escenario. Hacía pocos días que la Unión Europea se había comrometido en Lisboa a montarse en el tren de la nueva economía, y ahora desciende al continente africano para evitar la caída en el abismo de toda esta región, rica in recursos naturales, pero que padece, como ninguna, hambrunas, guerras, epiJemias (SIDA) y flagrante corrupción... La agenda de El Cairo ha sido dividida en res sesiones para abordar los capítulos socioeconómico, político y desarrollo. Demasiada agenda para dos días y distintas prioridades por ambos lados. Los europeos ponen énfasis en la necesidad de una integración regional del continente y de su incorporación a la economía mundial y presencia en la Organización Mundial Jel Comercio. Las cuestiones políticas incluyen derechos humanos, democracia, migración, xenofobia, refugiados, terrorismo, tráfico ilegal de armas...

Los africanos presentan demandas concretas: el perdón de la deuda, el desminado de territorios y la devolución de bienes culturales expoliados por las potencias coloniales. La deuda exterior africana ha sido el gran asunto de esta cumbre, que concluyó sin grandes novedades: Europa está dispuesta a ayudar si los países africanos emprenden reformas profundas políticas y económicas, que los conviertan en mercados atractivos para los capitales privados. En 20 años la deuda externa se ha triplicado, aproximadamente $\$ 350$ mil millones. Los paises africanos piden a la Unión Europea que les alivie de su deuda externa, una carga que estrangula sus precarias economías. Las respuestas concretas fueron individuales. El canciller alemán Gerhard Schröder anunció el perdón de la deuda por valor de 700 millones de marcos a 30 de los países más pobres. Francia podría anunciar una medida similar. El presidente Aznar prometió condonar el $14 \%$ de la deuda total africana con España. El óbolo de la viuda lo puso el rey marroquí, Mohamed VI, quien anunció "la anulación de todas las deudas que tienen los países menos desarrollados de África con Marruecos, y la eliminación de las barreras arancelarias para la importación de productos de esos países a Marruecos".

Respecto a la deuda se llegó al acuerdo de que "altos funcionarios de una comisión euro-africana tomarán las medidas necesarias para preparar un informe sobre la deuda externa africana, que será estudiado, en un razonable período de tiempo, a nivel ministerial en el marco del seguimiento de los acuerdos de la 
cumbre". Es decir, se toma nota del problema y se crea una comisión. Algo semejante se determina para el desminado de los países en conflicto y la devolución de los bienes culturales expoliados. Estos dos últimos reclamos dan a entender que en este encuentro euro-africano hubo momentos de tensión en el tono de algunos oradores. El presidente de Argelia y el Secretario de la reunión, Salam Ahmed Salam, tuvieron a bien recordar que en 1888 las potencias europeas se repartieron el continente, un continente muy rico en recursos naturales. Y lo que hoy pide África es una "asociación estratégica" que le permita alcanzar el bienestar y el progreso. El orador más agresivo fue Gaddafi, el líder libio, quien acusó a Europa de exportar la corrupción y la guerra, e instó a los europeos a "romper su dependencia de Estados Unidos". Esta intervención sirvió a enfriar el propósito constructivo de la cumbre.

En forma directa e indirecta tenían que aflorar otros problemas políticoculturales que carcomen las economías de bastantes países africanos: las dictaduras y los golpes de Estado que tronchan cualquier democracia e irrespetan los esenciales derechos humanos; la permanente xenofobia que alimenta guerras civiles e interestatales; el terrorismo y el tráfico de armas; la debilidad de las instituciones gubernamentales..., y no podía faltar una referencia al SIDA, que amenaza la existencia de una quinta parte de la población en algunas zonas o países. En esos días se estaba hablando de la presencia de ciertas hambrunas (Etiopía...) a causa de las prolongadas sequías y de las inundaciones de Mozambique... El perdón de la deuda se condicionaba a la revisión de aquellos problemas, no nacidos de desastres naturales, sino de la irresponsabilidad de determinados gobiernos o de grupos irreconciliables. El delegado alemán, Joschka Fischer, ya advirtió a su llegada a Egipto: "No podemos contemplar la deuda africana en su conjunto, porque no hay una solución igual para todos". La solución que ofrece la Unión Europea es el perdón en algunos casos, la negociación en otros, y la adopción de planes de saneamiento económico en todos, con la garantía de que los recursos que se liberen no se dedicarán a gastos militares o suntuarios" (Larraya, J.M y Esteruelas, B.: Europa intenta salvar el abismo que separa a África de la globalización. El País, 3 de abril de 2000. África pide a la UE soluciones radicales, rápidas y originales para salir de la pobreza. El Pais, 4 de abril de 2000)

He introducido la cumbre de El Cairo con el subtítulo de "una globalización mutilada", en un continente tan alejado no sólo de la nueva economía, sino de la más simple economía. ¿Cómo distinguir causas, cómo distribuir culpabilidades en esa historia colonial y cómo encontrar soluciones adecuadas a cada país? Siendo África, en su conjunto, el continente más excluido, los problemas de la globalización no se limitan a El Cairo. En el mismo mes de abril hay tres eventos que nos introducen en las entrañas de la globalización, desde una perspectiva más intercontinental. ¿Por qué Kofi Annan, Secretario de las Naciones Unidas, no se hizo presente a la reunión de El Cairo? 


\section{El informe de Kofi Annan para el siglo XXI}

Coincidiendo con la reunión de El Cairo, Kofi Annan presenta un plan de acción de las Naciones Unidas que sirva de agenda para la reunión de líderes mundiales, a celebrarse en Nueva York en septiembre próximo. Las Naciones Unidas deben adaptarse para cumplir su misión, actualizada al siglo XXI. La reestructuración del funcionamiento y la mentalidad de la ONU serán las nuevas armas para luchar contra el hambre, la pobreza y las guerras. "Nuestro reto principal es aseguramos de que la globalización se convierta en una fuerza positiva para toda la población mundial, en vez de dejar en la cuneta a miles de millones de personas". Desde 1945, año de la fundación de la ONU, hasta nuestros días, han aparecido nuevos problemas: una población de 6.000 millones de personas (el doble que en 1945), el aumento de las guerras civiles, el fenómeno de las limpiezas étnicas, la plaga del SIDA, los problemas medioambientales ... y un $25 \%$ de la población mundial que vive con menos de un dólar al día.

Este "plan de acción para el siglo XXI" invita a los Estados de los 188 países miembros a "gobernar más unidos", a fin de beneficiarse de las oportunidades que ofrece la globalización y no permitir que se agrande la fosa entre pudientes y pobres. Los gobiemos deben multiplicar los esfuerzos para eliminar la pobreza absoluta, mejorar la educación, la seguridad, la salud y la protección del medio ambiente. Kofi Annan pone como objetivo disminuir a la mitad la pobreza absoluta, de aquí al 2015; reducir en cinco años en un $25 \%$ la tasa de infección del SIDA, y garantizar la enseñanza primaria a todos los niños para el año 2015. El plan integra la cooperación de organizaciones privadas, la expansión del Intemet a fines sociales y el aprovechamiento de las oportunidades que ofrece la globalización.

Los objetivos generales se deben traducir en programas concretos, Hay que integrar el Internet en los nuevos proyectos de la ONU. "Debemos luchar contra las resistencias culturales de este nuevo medio". También "los países ricos deben abrir sus mercados a los productos de las naciones más pobres y garantizar una mayor flexibilidad de la deuda". La ONU invita a las multinacionales tecnológicas para que se incorporen al diálogo con las naciones; más específicamente, para facilitar las comunicaciones en casos de desastres naturales o crisis humanitarias. En este proceso de desarrollo no se puede olvidar el tema del medio ambiente. Por ello Kofi Annan pide a los países miembros que ratifiquen el protocolo de Kyoto, de 1998, para tratar de reducir en un $60 \%$ la emisión de gases de efecto invernadero.

Estos serían algunos de los nuevos instrumentos para enfrentar los nuevos problemas. La creación de un cuerpo de voluntarios que entrene a técnicos de países en desarrollo en el uso y oportunidades del Internet. Crear una red de salud por Internet para 10.000 hospitales y clínicas de países en desarrollo. Un nuevo equipo sobre el terreno, provisto de teléfonos satélite y diverso material de comunicación, que mejore la capacidad de respuesta de la ONU en casos de 
desastres naturales y crisis humanitarias. Con ayuda de técnicos del Banco Mundial e instituciones privadas elaborar respuestas concretas para mejorar las oportunidades de empleo juvenil. Kofi Annan pone sobre el tapete la reforma del Consejo de Seguridad, para reforzar la legitimidad de las Naciones Unidas ante estas nuevas realidades. (Bassir Pour, A. L'ONU présente "un plan d'action pour la XXIe siécle". Le Monde, 4 avril 2000. Piquer, I.: Annan anuncia un ambicioso plan para la ONU del nuevo milenio. El País, 4 de abril de 2000)

Más adelante diremos que el Banco Mundial duda de que puedan lograrse estos objetivos de la reducción de la pobreza, "salvo que el crecimiento de la economía se mantenga, alcance a esos países y se detenga la creciente distancia entre ricos y pobres", de acuerdo al informe de Indicadores del Crecimiento Mundial 2000, presentado en la reunión del Banco Mundial y Fondo Monetario Internacional, tenida en Washington, en abril de 2000. Sumando y restando puntos, se va ampliando el lado menguante de la globalización desde la cumbre de Bangkok, la reunión de El Cairo, el plan de acción de Kofi Annan, y más recientemente las dos concomitantes reuniones del grupo de los 77 (G-77), países del Sur, en La Habana, y del FMI, BM. y G-7, en Washington.

\section{La reunión del G-77: mucha retórica y pocos resultados}

Como era de esperar, los diarios y el Internet han prestado más tiempo y atención a la reunión de Washington que a "la cumbre del Sur", reunida en La Habana del 11 al 15 de abril. Se pretende agrupar a 133 países que engloban las cuatro quintas partes de la población mundial, entre ellos, China. Se trata de países distantes y diferentes no sólo por su tamaño y extensión geográfica, sino también por el desarrollo de sus instituciones políticas y gubernamentales. Aunque había reclamos comunes, también existían intereses diferentes que han dificultado la propuesta de soluciones conjuntas. En la agenda preparatoria había cuatro puntos principales: la globalización de la economía, las relaciones NorteSur, la colaboración Sur-Sur y el acceso a la ciencia y tecnología. Se buscaba una estrategia común frente a los países ricos y en contra del subdesarrollo.

Las estadísticas presentadas muestran el abismo entre el Norte y el Sur. El $20 \%$ más rico del globo consume el $86 \%$ de lo que se produce, mientras que el resto, un $80 \%$, consume apenas un $14 \%$. Unas 1.300 millones de personas (según cifras de la ONU) viven con menos de un dólar al día; 800 millones carecen por completo de servicios de salud y 849 millones de personas padecen desnutrición; 260 millones no pueden ir a la escuela. La servidumbre de la deuda externa del Tercer Mundo, 2,5 billones de dólares, es un lastre asfixiante y absorbe el $25 \%$ de las exportaciones. El SIDA diezma África y 800 millones de personas pasan hambre; 204 millones de ellos en la India y 164 millones en China... Se dirá que todas estas estadísticas claman al cielo y explican que la reunión de La Habana haya tenido una tonalidad más bien agresiva. 
"Los pobres tendremos que acabar de darnos cuenta de que sólo unidos podremos lograr que los ricos nos escuchen; que sólo unidos podemos defender con éxito nuestro derecho a la vida, al desarrollo, a la cultura y a la justicia social". Pero, al parecer, no se logró dicha unidad porque los intereses y los sistemas políticos del mundo pobre son muy diferentes. También es distinto el nivel de desarrollo; algunas naciones subdesarrolladas han prosperado, otras se hallan en recesión y otras están inmersas en regímenes feudales que frenan cualquier progreso. Con cierta razón, un invitado europeo comenta: "Si a la cumbre del Sur asistieron 122 de los 133 países que pertenecen al grupo de los 77, en los pasillos había 180 posturas diferentes". El presidente de Venezuela —único mandatario latinoamericano presente en la reunión - tuvo la iniciativa de señalar que, además de las exigencias a los países industrializados, "hay que trabajar en el interior del grupo de los 77: antes de mirar la paja en el ojo ajeno, hay que mirar la que tenemos en el nuestro".

Kofi Annan fue bien explícito en señalar que los países sólo pueden desarrollarse si tienen democracia. "Un Estado que se niega a abrir un proceso de apertura democrático a las instituciones derivadas de éste, impide el desarrollo y el progreso de su pueblo, denegándoles la oportunidad de una interacción plena con el resto del mundo". No se refirió explícitamente a Cuba, cuyo índice de desarrollo humano es superior al de otros países con un producto per cápita mayor. Kofi Annan denunció el embargo de los Estados Unidos al régimen de Castro e hizo una favorable reflexión sobre sus logros sociales. Por su parte, las naciones subdesarrolladas pidieron a Kofi Annan "buscar el fortalecimiento del papel de las Naciones Unidas en el desarrollo de la cooperación internacional y tener mayor participación en esta institución".

De acuerdo a los reportes de las agencias, Fidel Castro sostuvo posiciones bastante agresivas, más propias de una tribuna política que de un plan de acción. "La hora actual no puede ser de ruegos a los países desarrollados, ni de sumisión..., sino de rescate de nuestro espíritu de lucha, de la unidad y cohesión en tomo a nuestras demandas... $\mathrm{O}$ nos unimos y cooperamos estrechamente o nos espera la muerte". Comparó la globalización con un barco, donde los pasajeros viajan en condiciones desiguales: una minoría, en cómodos camarotes, buena comida y acceso a la salud; y una abrumadora y doliente mayoría, en condiciones que semejan las horribles travesías del comercio de esclavos entre África y América en el pasado. De seguir ese curso irracional y absurdo, además de no arribar a puerto, seguro nos hundiremos todos". Fidel Castro incitó, más bien, a una sublevación contra el FMI y el actual orden económico, demandando la total condonación de la deuda, una campaña que él iniciara hace unos quince años. A propósito del viaje en barco, no podía faltar una alusión al drama del "niño balsero"...

El documento final tradujo todos estos reclamos en términos más conciliatorios: medidas de acceso a los mercados, recursos financieros, tecnología, y que el mundo desarrollado cumpla con la promesa de dedicar el $7 \%$ de su PIB al 
Programa de Asistencia Oficial al Desarrollo. Se solicitó "fortalecer el Grupo de los 77 e intensificar esfuerzos para revisar y reformar el sistema de la Organización Mundial del Comercio, como forma de mejorar el acceso a los mercados de interés para las naciones en desarrollo". Como la secretaría de esta reunión recibió 123 proyectos de cooperación —en algunos casos, ideas sin contenido-, el propio Kofi Annan pidió más rigor en el planteamiento de estas demandas, para que sean "más creibles y convincentes", aludiendo a la frivolidad de algunas de ellas. Así, con más pena que gloria, o, como dice un reportero, "con mucha retórica y pocos resultados" concluye la cumbre del Sur. (Arnárez, J. J. y Vicent, M.: Los paises en desarrollo debaten un plan contra los desequilibrios de la globalización. El País, 11 de abril de 2000. El G-77 busca una estrategia común frente a los países ricos. El País, 12 de abril de 2000. La cumbre del Sur concluye con mucha retórica y pocos resultados, El País, 15 de abril de 2000).

\section{La reunión de primavera del FMI y BM}

La calificada reunión de "primavera" levantó variadas y enfrentadas expectativas. Los informes preparados por los directorios del FMI, BM y ministros de finanzas del Grupo de los 7 (G-7) pronosticaban sólidos crecimientos de la economía mundial, superiores al $4 \%$ en el 2000 y de 3,9\% para el 2001. Sin embargo, en esta reunión volverá a repetirse que los promedios totales esconden las mayores desigualdades; por ello, la globalización aparece para unos como la "primavera del crecimiento" y para otros como la "primavera de las desigualdades". Además, en forma más bien anunciada que inesperada, la reunión se lleva a cabo cuando estalla el "viemes negro", 14 de abril, con brusca caída de las cotizaciones del Nasdaq, que contagia al resto de valores de Wall Street, dejando pendiente un interrogante: ¿se profundizará la caída en un siguiente "lunes negro"? ¿Qué consecuencia tendría esta ruptura de la "burbuja" en el anunciado crecimiento mundial? Más en particular, no se iba a cuestionar la "primavera", sino el historial pasado y las funciones presentes del FMI y BM, atacados desde dos flancos diferentes. Se trataba de una reunión tachonada de enfrentadas expectativas.

\subsection{Las manifestaciones contra la "trinidad pagana"}

La policía norteamericana no estaba dispuesta a que se repitieran las acciones agresivas de diciembre de 1999, en Seattle. El gobierno movilizó, a tiempo, 1.500 policías equipados con los más diversos medios de control y locomoción. Los manifestantes integraban una amplia coalición de organizaciones sindicales, ecologistas, anarquistas, religiosas y humanitarias. Se trata de una coalición de más de 200 grupos llamada "Movilización para la Justicia Social". Había un ambiente festivo y cuatro consignas escritas en pancartas: no usar la violencia, física o verbal; no llevar armas; no llevar alcohol ni drogas y no atacar a la propiedad. Se trata de una poderosa oposición a la mundialización que atrae a miles de decenas de manifestantes organizados. 
Los reporteros de Le Monde agregan un dato interesante y muy a tomar en cuenta entre nosotros. Los organizadores de la manifestación dicen que "estas personas están coléricas porque saben que todo esto está mal, aunque no saben exactamente por qué. Nosotros les proporcionamos expertos que les dan los elementos necesarios para que su activismo sea más eficaz. Así, ellos aprenden a explicar, con documentos a la mano, el funcionamiento de las organizaciones financieras internacionales y los daños que causan, no sólo a los países pobres, sino también a los Estados Unidos. Se discuten las condiciones draconianas impuestas por las instituciones financieras internacionales en los préstamos al Tercer Mundo, el enfrentamiento con las multinacionales que abusan de la mano de obra barata y violan los derechos humanos de los trabajadores de los países pobres, al mismo tiempo que reducen el empleo en los países ricos, contribuyen a la destrucción del medio ambiente e imponen reglas comerciales que sólo benefician sus propios intereses". (De Beer, P.: Les opposants á la mondialisatión ont rendez-vous au FMI á Washington. Le Monde, 12 avril 2000)

Algunos comentaristas hablan de Washington como el "Seattle II", por cuanto los manifestantes atacan a la "trinidad pagana": Fondo Monetario Internacional, Banco Mundial y Organización Mundial del Comercio, instrumentos de la globalización para el empobrecimiento de los países en desarrollo. Los reclamos se alternan: "El Banco Mundial saquea el planeta: no más dinero para el petróleo, gas y minas”; “¿Quién debe a quién?”, se preguntan los manifestantes... "Las grandes corporaciones petroleras y mineras, que explotan las materias primas del Tercer Mundo, producen enormes destrozos humanos y medioambientales"... "Antes defendíamos los derechos civiles; ahora luchamos por los derechos humanos. Si la policía no nos deja manifestarnos estará violando la Constitución"... "La moralidad está antes que la legalidad"... Entre los manifestantes hay quienes enarbolan la Biblia y citan al profeta Isaías. Los más de 350.000 millones de dólares que deben los países pobres, en buena parte al FMI y BM, son el cimiento de las protestas. Larry Summers, secretario del Tesoro de los EEUU, había dicho: "aliviar la deuda de los países más pobres es un imperativo moral y económico". Pero los manifestantes no lo consideran suficiente; su tesis es que "la globalización económica en curso sólo beneficia a las grandes empresas multinacionales en detrimento de los países pobres".

Aunque externamente los manifestantes de Washington no desbordaron a la policía, ni hicieron destrozos contra la propiedad, como sucedió en Seattle, ellos consideran haber logrado un gran triunfo. "Me parece importante que desde el Norte la gente esté protestando contra lo que hacen el FMI y el BM, que están al servicio de las grandes compañías, que destruyen el mundo. El mensaje está dado y que el Fondo y el Banco digan que quieren cambiar ya es un triunfo". La próxima cita será en septiembre, en Praga. (Valenzuela, J. y Martínez de Rituerto: La cumbre del FMI comienza hoy bajo el "síndrome de Seattle". El País, $12 \mathrm{de}$ 
abril de 2000. La cumbre del FMI se celebra en medio de una implacable represión policial. El Pais, 17 de abril de 2000)

\subsection{EI FMI y el BM entre dos frentes de ataque}

En vísperas de iniciarse la reunión de Washington, el economista Jeffrey Sachs preanuncia el debate que se abrirá en torno a las funciones de ambas instituciones. El título predice la orden del día: "Bajar los humos". La reunión tiene lugar luego de la anticipada renuncia de M. Camdessus y en espera de la toma de posesión del alemán Hurst Kohler. "Las naciones ricas, y en especial los Estados Unidos, han utilizado ambas instituciones como instrumentos de la diplomacia financiera. EEUU y Europa las utilizaron para hacer llegar dinero a los países favorecidos - México, Rusia o el Este de Asia- en tiempos de crisis. Los enemigos del FMI y del Banco Mundial creen que los dos son demasiado grandes, demasiado poderosos y sobrepasan sus límites. EI FMI intenta dirigir las operaciones financieras de más de 50 países, e impone sus programas durante años e incluso décadas. Mantiene su influencia porque EEUU insiste en que los países más pobres implanten programas del FMI cuando se les reduce la deuda o reciben otro tipo de ayuda económica. El Banco Mundial presta dinero a docenas de países a través de cientos de programas, pero muchos receptores tienen acceso al mercado de capital privado, de modo que los créditos del Banco Mundial constituyen una pequeña parte de lo que esos países pueden obtener prestado en el resto del mundo a través de mecanismos normales de mercado".

Con estos antecedentes, Jeffrey Sachs resume algunas de las conclusiones y recomendaciones de la Comisión Meltzer, donde él participó. Con una plantilla de unas mil personas, el FMI no debería intentar administrar tantos países, so pena de caer en la superficialidad, arbitrariedad, intromisión en la soberanía y malos resultados. Ambas instituciones deben reducirse a lo que son sus responsabilidades fundacionales: el FMI debe centrarse en mantener la estabilidad macroeconómica mundial facilitando préstamos de corto plazo en situación de emergencia. El Banco Mundial se preocupará por los países pobres, donde la necesidad es más apremiante, reduciendo sus operaciones en aquellas naciones cuya solvencia les permite recurrir al capital privado. La Comisión Meltzer recomendó la condonación de la deuda a los países más pobres y endeudados para que puedan independizarse del FMI. Sin embargo, "el Gobierno de los EEUU y los directores del FMI y del Banco Mundial se oponen a estas recomendaciones. En su arrogancia, creen que ellos son los que tienen que decidir el destino del mundo en vías de desarrollo, a pesar de que sus programas fracasan. Dentro de poco se les van a bajar los humos al FMI y al Banco Mundial porque sus programas no funcionan lo suficientemente bien como para justificar la autoridad que exigen". (Sachs, J.: Bajar los humos. El País, 10 abril de 2000) J. Sachs anunciaba, de víspera, uno de los frentes contestatarios de la reunión de Washington. 
$\mathrm{Al}$ iniciarse la reunión, tanto el FMI como el Banco Mundial deberán enfrentarse al doble ataque de quienes les acusan de dispendio de fondos y, en el otro extremo, de no llevar la ayuda a los países más desprotegidos. La legitimidad de estas instituciones se centra en el papel que deben jugar en la lucha contra la pobreza y su aporte al crecimiento mundial. Los manifestantes insisten en el tema de la reducción de la deuda, los perjuicios de la mundialización y los efectos perversos de la apertura de los mercados para los países en desarrollo, que benefician esencialmente a las multinacionales.

Frente a la última línea de ataque, los dirigentes del FMI y Banco Mundial se defienden afirmando que ellos persiguen los mismos objetivos que los manifestantes. En repetidas ocasiones, James Wolfensohn, presidente del Banco Mundial, ha dicho: "Es algo desmoralizador ver a personas que se movilizan en pro de la justicia social cuando eso es exactamente lo que hacemos cada día. No me opongo a discutir estos problemas y lamento que el debate sea bloqueado por algo que impide reunimos". Sin duda, estas palabras de Wolfensohn rezuman sinceridad para quienes hayan leído su informe sobre "La otra crisis", de octubre de 1998. (ECA, 1998; pp. 1003-1009) Algo distinta es la respuesta de Stanley Fischer, presidente interino del FMI: "La mundialización representa el único camino de hacer llegar a la población mundial al mismo nivel de los países industrializados... Lo que intentamos hacer es ayudar a la población de los países pobres a tener las mismas oportunidades que los países ricos. Los habitantes de los países ricos lo lograron abriendo sus fronteras". Indudablemente, esta simple tesis es algo cuestionable.

El enemigo más encarnizado y más poderoso es el Congreso estadounidense, de donde vienen los ataques virulentos, presentados por la comisión A. Meltzer, la cual recomienda una reducción drástica de las funciones de ambas instituciones. "En Washington, la administración Clinton quiere, también ella, reducir el papel de las instituciones financieras internacionales, a beneficio del sector bancario privado". El secretario del Tesoro, Larry Summers, afirmó: "La Banca mundial y las Bancas de desarrollo regionales (como la Banca latinoamericana o la Banca asiática) no tienen nada que hacer en los países que tienen acceso a los mercados de capitales y deben concentrar sus esfuerzos en la lucha contra la pobreza y las enfermedades como el SIDA y la malaria". Si unos hablan de reducción drástica de funciones, otros manifestantes se pronuncian por su cierre y desaparición. Nunca estas instituciones se habían visto tan enfrentadas a esta doble línea de ataque.

En la reunión se intercalan las réplicas y contrarréplicas. Stanley Fischer responde a las ONG's: “No es aceptable decir que las políticas macroeconómicas no son las mismas en todas partes y que los países en desarrollo no tengan los mismos derechos que los países ricos". Sin embargo, Joseph Stiglitz, anterior economista jefe del Banco Mundial, declaró que "es necesario encontrar una manera de dar mayor representación al mundo del trabajo y de la sociedad civil 
y cambiar la repartición de los derechos de los países", porque ahora los países sometidos a los programas del FMI tienen la sensación de hallarse "sin voz y sin poder frente a las políticas definidas por instituciones claramente dominadas por el G-7 y la comunidad financiera". Stiglitz refleja así la situación de los países pobres, que apenas ha mejorado en los últimos años y para quienes "la poción mágica de la mundialización y del libre cambio sigue siendo un brebaje desagradable e ineficaz". A modo de interludio, por esas fechas apareció un artículo de J. Stiglitz, What I learned at the world economic crisis, en el que critica acremente las políticas económicas del FMI luego de la crisis financiera del sudeste asiático. Este artículo se ganó una réplica similar del economista Rudi Dornbuchs, coautor con S. Fischer, del conocido texto de Macroeconomía...

En el último día de la reunión, 16 de abril, los Estados Unidos volvieron a insistir: "que los que acuden al FMI sean obligados a devolver lo antes posible sus préstamos, a fin de evitar que la institución se vea comprometida en medidas de largo plazo, función que corresponde a la Banca mundial. El Fondo (FMI) debe dedicarse esencialmente a la concesión de disponibilidades de tesorería en tiempo de crisis". Como en esta sesión se hallan presentes los 24 representantes del Comité Financiero y Monetario Internacional (CFMI), oponiéndose a la tesis del Congreso, estos representantes han reafirmado la función "única" del FMI de velar por la estabilidad del sistema monetario y financiero mundial y su capacidad, por su carácter universal, de ayudar a todos los miembros". El nuevo ministro de finanzas francés, Laurent Fabius, declaró: "El FMI debe ayudar a todos los países, en particular a los más pobres, a lograr un desarrollo durable. Este apoyo debe ser universal. Sé que algunos piensan de otra manera y, bajo pretexto de una racionalización, tratan de contraer la función del FMI en favor de los más pobres. No es esa la posición de Francia".

De este entramado de posturas divergentes y de las críticas a la administración interna del FMI se llegó a concluir que esta institución debe dar pruebas reales de una mayor transparencia administrativa. “¿Dónde va el dinero? ¿Cómo se definen los programas impuestos a los países, como contrapartida a la asistencia financiera? ¿Se toman en cuenta las consecuencias sociales que provocan? ¿Quién controla estas instituciones? Más en concreto, se postularon una serie de normas y una superintendencia, independiente del Consejo Financiero y Monetario Internacional. L. Fabius concluyó: "La idea es que los responsables escogidos para esta unidad se vean comprometidos a dar cuenta de estas actividades y que todo esto no quede sólo al interior del FMI". Se han propuesto una serie de salvaguardas y directrices; sin embargo no se ha cuestionado lo fundamental de su trabajo. (De Beer, P. y Stern, B.: Le röle et l' éfficacité de FMI et de la Banque mondiale contestés. Le Monde, 14 avril 2000. Le FMI et la Banque mondiale devront faire preuve de plus de transparence. Le Monde, 17 avril 2000) 


\subsection{Reajustando la economía mundial}

El telón de fondo es de euforia. Para el Grupo de los 7 (G-7), "las perspectivas son magníficas para la economía": $4,2 \%$ de crecimiento mundial en el 2000 y $3,9 \%$ en el 2001 ; en la zona del euro se espera $3,2 \%$ para ambos años, y Latinoamérica crecería $4 \%$ en el 2000 y $4,7 \%$ en el 2001. Pese a las magníficas expectativas, "hay que estar vigilantes", dijo L. Summers, secretario del Tesoro de los EEUU. La razón: "el fantasma de un "lunes negro" planea sobre las bolsas mundiales". Para tranquilizar los espíritus, se dirá que los pilares de la economía estadounidense son muy sólidos. "Vamos a tener un buen año" dijo Clinton. "No hay riesgo de crash en las bolsas europeas", dijo L. Fabius. Pero los fantasmas son algo más que fantasmas y se habla del final de la "exuberancia irracional", dado el elevado nivel de endeudamiento en que ha caído buena parte de la población norteamericana para jugar en bolsa de valores. Se espera que Alan Greenspan, presidente de la Reserva Federal, eleve de medio punto las tasas de interés, para contener el frenesí de esta demanda de créditos especulativos. "La época del dinero fácil ha terminado; ahora toca ser más selectivos", dijo el vicepresidente de la General Electric. No hubo "Iunes negro", pero su fantasma planea sobre el mundo de la especulación.

Más digna de preocupación es la situación del hemisferio Sur. También en esta reunión, J. Wolfensohn nos presenta "la otra crisis"; "El Banco Mundial duda que pueda reducirse la pobreza a la mitad en 2015". Se vuelven a presentar las mismas estadísticas leídas en La Habana. El mayor problema al desarrollo se presenta en África, por similares razones a las expuestas en El Cairo. "Hay países en los que el pago de la deuda se lleva más del $60 \%$ del presupuesto y no queda casi nada para el desarrollo. Muchos de estos países recibieron créditos en el pasado, que no fueron debidamente aplicados o que no fueron dirigidos a objetivos de desarrollo humano". (Martinez, R. R.: El FMI debate mecanismos para atajar futuras crisis económicas internacionales. El Pais, 17 de abril de 2000. El Banco Mundial duda de que pueda reducirse a la mitad la pobreza en 2015. El Pais, 14 de abril de 2000) África es la parte del mundo que recibe más recursos del FMI y del Banco Mundial; 32 de sus países reciben trato de alivio para su deuda y, por ello, defienden los planes de ambas instituciones. "Pero exigen que la comunidad internacional trate a África como un igual en la escena comercial, sin barreras proteccionistas y pagando precios justos por las materias primas... África vive en la pobreza, pero no es pobre". El representante de Costa de Marfil dijo: "La corrupción, un mal endémico en África, no debe impedir que siga llegando la ayuda".

Mientras que los ministros de finanzas del G-7 intentan tranquilizar a los mercados, sin hacer referencia a la crisis bursátil, las bolsas de valores y los reclamos de los manifestantes les recuerdan que en el hemisferio Norte pueden desincharse las "burbujas", y que en el hemisferio Sur cunde la "globalización 
mutilada". (Las bolsas de valores y los manifestantes cercan al G-7. El País, 16 de abril de 2000).

\subsection{M.Camdessus contempla el FMI desde París}

Sólo es posible extractar algunas reflexiones de esta entrevista de nueve páginas. Estas preguntas-respuestas sirven a lanzar algunas luces sobre el proceso de réplicas y contraréplicas en torno a estas instituciones financieras internacionales. Fuera del FMI, Camdesus podrá expresarse con cierta libertad y tal vez sinceridad. Sin duda la reflexión en clave-mayor es el título escogido por la reportera de El Pais: "La pobreza puede hacer estallar este sistema". Camdessus dice que "los manifestantes nunca me impidieron hacer mi trabajo, pero ellos expresan el miedo a esta mundialización de la que sólo ven los riesgos". Cuestionado sobre la receta única del FMI, Camdessus responde: "Nosotros nunca dijimos que había que recortar en salud, educación, sino con menos gasto hacer más. Lo que hemos atacado no es el gasto social, sino el gasto improductivo". Algunas respuestas rondan la frialdad o el cinismo burocrático: "La historia humana es trágica por naturaleza y, cuando cambia para mejorar las cosas, siempre hay costos indirectos. Sabíamos perfectamente que desprenderse de las empresas públicas y la flexibilidad laboral iban a dejar gente en la calle. Pero son fenómenos transitorios en una estrategia que me parece ha servido al desarrollo humano. Por doloroso que sea, era necesario, por todo esto, para hacer empresas más productivas".

Camdessus no cree que el crecimiento sea la panacea para todos los males de la humanidad, y por ello apoya a quienes piden en las calles el $0,7 \%$ del PIB (para ayuda asistencial) y la reducción de la deuda de los 40 países más pobres. "Es un escándalo que en tiempo de prosperidad como éste, cuando el conflicto Este-Oeste ya no existe y ha permitido reducir gastos militares, la ayuda al desarrollo, en lugar de crecer, haya bajado". "Nos hace falta desarrollar valores que hagan sentirse a cada uno responsable de la estabilidad y crecimiento del sistema". Preguntado sobre la responsabilidad del FMI en la concesión de créditos que sólo endeudan más a países como Argentina, Brasil, Indonesia, Rusia..., Camdessus responde: "Aunque hemos hecho todo lo que está en nuestras manos para combatir este nuevo capitalismo basado en la corrupción, el nepotismo y el amiguismo, poco podíamos hacer... Este tipo de capitalismo no sólo se ha dado en Rusia; donde había aparecido en forma más sangrante había sido en Asia. En Tailandia, Corea y particularmente en Indonesia... Señor Yeltsin, usted tiene los mismos problemas que esos países asiáticos; si no combate la corrupción y el nepotismo, su sistema se va a derrumbar". ¿El mercado es un bien supremo, un fin en sí mismo, que justifica todos los medios? "No hay que considerar al mercado como una divinidad a la que hay que adorar. Se ha visto que el mercado solo, sin regulación pública eficiente, no funciona bien y puede crear situaciones sociales y de poder destructoras para la democracia y para el propio mercado. Pero 
es el sistema más eficaz que hemos conocido, cuyos vicios se trata ahora de corregir"... "No soy jurista, pero, si hay que enviar a la cárcel a los corruptos, acaparadores y explotadores de la pobreza humana, me parece muy bien"... "El FMI se ha convertido en el chivo expiatorio de todos los males de la mundialización. Creo que es una visión errada. Uno de mis empeños continuados ha sido precisamente convencer a los paises de que no deberían desatender lo social, pidiéndoles que hicieran algo para atemperar el impacto de la liberalización sobre los desprotegidos"... Camdessus dice discrepar de las críticas de la Comisión Meltzer: "Piden que el Banco Mundial deje de conceder continuos créditos o subvenciones, lo que es otra manera de decir que el Banco tiene que cerrar. Pero el señor Meltzer no habla en nombre del mundo entero, y las políticas que yo he aplicado han sido votadas por unanimidad en el seno de una institución donde están representados los 182 paises; así que me tomo con un poco de sal y pimienta esas críticas".

Pregunta final. Además de la falta de palabra, la irresponsabilidad y la codicia, ¿qué más le ha sorprendido de la condición humana, tratando con los que están al frente del poder? "La generosidad. No hay muchos como Mandela, pero sí hay muchos que sueñan con ser Mandela. Hay que animarlos a serlo sin que tengan que pasar antes 20 años en la cárcel. Las crisis me han demostrado que hasta los más corruptos son susceptibles de mejorar un poco; así que hay que trabajar para ello". (Roma, P.: La pobreza puede hacer estallar este sistema. El País, 24 de abril de 2000).

\section{Y después de Washington... ¿Washington?}

Desde hace tres años se viene hablando de estructurar una nueva "arquitectura financiera internacional". El Congreso de la Internacional Socialista, celebrado en noviembre de 1999 , lo intercalaba como uno de los puntos de agenda de la Declaración de París: "Reformar el Fondo Monetario Internacional, el Banco Mundial y la Organización Mundial del Comercio ("la trinidad pagana" de los manifestantes) para adaptarlos a las nuevas realidades; Asegurar una mayor transparencia del sistema financiero internacional, a través de reglas". (ECA 2000; p.60) En Washington, los manifestantes son más drásticos en sus demandas: el FMI y el BM deben convertirse del servicio a las multinacionales hacia el servicio de los países pobres o deben cerrarse. El Congreso de los EEUU, apoyado en la comisión Meltzer y en su postura ultraliberal desearía -y lo seguirá pidiendo- recortar las funciones de ambas instituciones, "porque opina que malgastan el dinero de los contribuyentes, fundamentalmente norteamericanos", para ceder este espacio al capital financiero privado. Dadas las prósperas perspectivas de la economía mundial, en particular la norteamericana, el mercado y la nueva economía serán los reguladores del crecimiento mundial. Es conveniente condonar o reducir la deuda externa del tercer mundo para que estos países puedan abrir sus fronteras a la globalización. 
En Washington se refuerza la tesis de Washington; pero esta tesis no aproxima sino que amplía la brecha entre acreedores y deudores de la economía mundial. Esto ha quedado confirmado en este breve recorrido de reuniones y cumbres internacionales. Por ello, desde Seattle hasta Washington, desde el oeste al este de los EEUU, se renuevan las manifestaciones en defensa de los derechos humanos y en contra de una "globalización mutilada". Si en el hemisferio Norte se renuevan las manifestaciones a favor de los derechos humanos del hemisferio Sur, es normal que algo similar surja entre nosotros. No significa esto movilizar manifestantes delante de Casa Presidencial, porque suficientes manifestaciones se llevaron a cabo - para quien quiera ver y escuchar- en las recientes elecciones de marzo. Se trata de reflexionar y analizar los pros y contras del proceso de globalización, de conocer mejor sus principios y su mecanismo de funcionamiento. Por esta razón, hemos venido haciendo, junto con tantos otros estudiosos, una lectura histórica de esta simbiosis de "neoliberalismo y globalización" (ECA, 1998; pp. 893-907. ECA 2000, pp. 59-77 y 121-127) recogiendo testimonios autorizados de ambas costas del Atlántico.

Esto tiene su aplicación práctica en este primer semestre de 2000 cuando, junto al título en mayúsculas "La economía aún no despega", se agrega el subtítulo: "Expectativas para el segundo trimestre son positivas". Estos subtítulos esconden un peligro; primero que se trata de expectativas favorables para algunos, pero no de realidades objetivas para todos. Lo segundo, que la pasada década de los noventa nos ha enseñado que nuestra economía de menos Estado y más libre mercado no ha resuelto el problema estructural del desempleo-pobreza, y más bien ha propiciado la concentración de riqueza y la disparidad de ingresos. Lo tercero, y valga la comparación, que esto sería resignarse a que nuestra economía avance como un barco de vela, movido por el viento de la recuperación internacional-continental, renunciando a montar o a reparar nuestro interno motor de la economía, que por cierto tiene muchas piezas y bielas desarticuladas, como nos lo ha mostrado, entre otros documentos, el estudio inicialmente citado de Roberto Rivera Campos. Como dijo M. Camdessus: "La pobreza puede hacer estallar este sistema". 